\title{
İnfantil hemanjiomların tedavisinde topikal beta-blokerlerin etkinliği
}

\author{
The efficacy of topical B-blockers in the treatment of infantile hemangiomas
}

\author{
Gökçe Pınar Reis, Ali Fettah, Ali Akyiğit, Atilla Çayır, Burcu Volkan
}

Gönderilme tarihi:04.02.2020

Kabul tarihi:03.06.2020

Özet

Amaç: İnfantil hemanjiomlar $(\mathrm{IH})$ endotel hücrelerinin benign proliferasyonlarıdır. Çocukluk çağının en sık görülen benign tümörleridir. İH'ın çoğu kendiliğinden gerilerken, yaklaşık \%10'u medikal tedavi gerektirir. İH'ın medikal tedavisinde kortikosteroidler, interferon ve vinkristin eskiden beri kullanılan ajanlardır. Son yıllarda topikal beta-blokerler teröpatik etkinliklerinin gösterilmesi ve sistemik yan etkilerin daha az görülmesi nedeniyle İ tedavisinde alternatif bir tedavi yöntemi olarak kullanılmaya başlanmıştır. Bu çalışmada, topikal beta-bloker kullanılan yüzeyel İH hastalarının epidemiyolojik özellikleri ve tedavi etkinliğinin değerlendirilmesi amaçlanmıştır. Gereç ve yöntem: Erzurum Bölge Eğitim ve Araştırma Hastanesi Çocuk Hematoloji-Onkoloji Polikliniği'ne Nisan 2015 ile Mayıs 2017 tarihleri arasında başvuran, yaşları 0-36 ay arasında olan 30 hasta çalışmaya dahil edildi. Yüzeyel hemanjiyomu olan hastalara lezyon bölgesine $\% 0,5$ timolol maleate solüsyon, sabah ve akşam ikişer damla olacak şekilde uygulandı.

Bulgular: Tedavi öncesi hemanjiomların çapı ortalama $2,5 \pm 1,5 \mathrm{~cm}$ iken, tedavi sonrası 1,3 $\pm 0,8 \mathrm{~cm}$ olarak belirlendi $(p<0,0001)$.

Sonuç: Lezyonda belirgin gerilemeye yol açması nedeni ile timolol kullanımı ümit vadetmektedir. Ancak daha geniş çaplı ve kontrollü-randomize çalışmalara ihtiyaç olduğu da bir gerçektir.

Anahtar kelimeler: Hemanjiom, lokal, tedavi.

Reis GP, Fettah A, Akyiğit A, Çayır A, Volkan B. İnfantil hemanjiomların tedavisinde topikal beta-blokerlerin etkinliği. Pam Tıp Derg 2020;13:541-546.

\begin{abstract}
Purpose: Infantile hemangiomas are benign proliferation of endothelial cells. It is the most common benign tumor of childhood. While the most of $\mathrm{IH}$ is spontaneously regressing, about $10 \%$ requires medical treatment. Corticosteroids, interferon and vincristine have long been used in medical treatment of $\mathrm{IH}$. In recent years, topical beta-blockers have been used as an alternative treatment modality for the treatment of IH because of their therapeutic efficacy and low systemic side effects. The aim of this study was to evaluate the epidemiological features and treatment efficacy of superficial IH patients using topical beta-blockers.

Materials and methods: 30 patients, aged between 0-36 months, who applied to the Pediatric HematologyOncology Polyclinic of the Erzurum Regional Education and Research Hospital between April 2015 and May 2017 were included in the study. In patients with superficial hemangioma, $0.5 \%$ timolol maleate solution was applied to the lesion area, two drops in the morning and in the evening.

Results: While the mean diameter of hemangiomas before treatment was $2.5 \pm 1.5 \mathrm{~cm}$, it was determined as $1.3 \pm 0.8 \mathrm{~cm}$ after treatment $(p<0,0001)$.

Conclusions: The use of timolol is promising because it causes a marked regression in the lesion. However, it is a fact that wider-scale and controlled-randomized studies are needed.
\end{abstract}

Key word: Hemangioma, local, treatment.

Reis GP, Fettah A, Akyigit A, Cayir A, Volkan B. The efficacy of topical B-blockers in the treatment of infantile hemangiomas. Pam Med J 2020;13:541-546.

Gökçe Pınar Reis, Dr. Öğr. Üye. K.T.Ü Tıp Fakültesi Çocuk Hematoloji Onkoloji Kliniği, Trabzon, Türkiye, e-posta: gpinarreis@gmail.com (orcid. org/0000-0001-9684-3595) (Sorumlu Yazar)

Ali Fettah, Doç. Dr. Dr. Sami Ulus Çocuk Hastanesi, Çocuk Hematoloji Onkoloji Kliniği, Ankara, Türkiye, e-posta: alifettah@gmail.com (orcid. org/0000-0003-4109-2143)

Ali Akyiğit, Uzm. Dr. Erzurum Bölge Eğitim ve Araştırma Hastanesi, Çocuk Sağlığı ve Hastalıkları Kliniği, Erzurum, Türkiye, e-posta: draakyigit1@ gmail.com (orcid.org/0000-0002-8697-6287)

Atilla Çayır, Doç. Dr. Erzurum Bölge Eğitim ve Araştırma Hastanesi, Çocuk Endokrinoloji Kliniği, Erzurum, Türkiye, e-posta: dratillacayır@gmail. com (orcid.org/0000-0001-9776-555X)

Burcu Volkan, Uzm. Dr. Marmara Üniversitesi Pendik Eğitim ve Araştırma Hastanesi, Çocuk Gastroenteroloji Kliniği, İstanbul, Türkiye, e-posta: burcupisgin@yahoo.com (orcid.org/0000-0002-0528-3826) 


\section{Giriş}

Infantil hemanjiomlar $(\mathrm{IH})$ yaşamın ilk 8 haftasında ortaya çıkan endotel hücrelerinin benign proliferasyonlarıdır. Çocukluk çağının en sık görülen benign tümörleridir. Matür bebeklerin yaklaşık $\% 5$ 'inde, prematüre bebeklerin ise üçte birinde görülmektedirler [1]. Infantil hemanjiomların progresyonu 3 evrede tanımlanır. Birinci evre olan proliferatif faz yaşamın ilk birkaç haftasında başlar ve 4-12 ay arasında tamamlanır. Büyük İH'ler de ise bu dönem bir yıldan uzun sürebilir. Proliferatif fazı takiben büyümenin durduğu plato evresi görülür. Plato evresini takiben ise lezyonun gerilemeye başladığı involusyon evresi başlar. Hemanjiomlar çoğu durumda 5-9 yıl arasında tam regresyona uğrarlar [2].

Bir yaşındaki çocuklarda İH insidansının \%510 olacağı tahmin edilmektedir [3]. Birinci derece akrabalarda pozitif aile öyküsü olması İH riskini artırır [4]. Çoğu hemanjiom sporadik olarak ortaya çıkmasına rağmen, otozomal dominant geçişler de bildirilmiştir [5]. Plasenta previa, preeklampsi, ileri anne yaşı, amniosentez ve koryon villus biyopsi işlemlerinin yapılması iH ile ilişkili bulunmuştur [6].

İnfantil hemanjiomların çoğu kendiliğinden gerilerken, yaklaşık \%10'u medikal tedavi gerektirir [7]. Hava yoluna ve orbitaya yerleşmiş, solunum zorluğu ve görme bozukluğu yapabilecek ciddi lezyonlarla birlikte baş ve boyun bölgesinde, özellikle yüz, kulak ve burun gibi bölgelere yerleşmiş, hem kozmetik sorunlara hem de ülser, kanama ve enfeksiyon gibi komplikasyonlara yol açabilecek hemanjiyomların tedavi edilmeleri gerekebilir.

İnfantil hemanjiomların medikal tedavisinde, kortikosteroidler, interferon ve vinkristin eskiden beri kullanılan ajanlardır. Nonselektif $\beta 1 / \beta 2-$ adrenerjik antagonist olan propranololün $\mathrm{IH}$ tedavisinde etkinliğinin gösterilmesinden sonra, propronolol sıklıkla kullanılan bir tedavi seçeneği haline gelmiştir [8]. Propranolol tedavisi ile bronkokonstrüksiyon, bradikardi, hipotansiyon, hipoglisemi, kardiyak performansta azalma ve kardiyak yetmezlik gibi yan etkiler görülebileceği için hastalar tedavi esnasında yakın takip edilmelidir [7]. Son yıllarda topikal beta-blokerler teröpatik etkinliklerinin gösterilmesi ve sistemik yan etkilerin daha az görülmesi nedeniyle $\mathrm{iH}$ tedavisinde alternatif bir tedavi yöntemi olarak kullanılmaya başlanmıştır [8-10].

$\mathrm{Bu}$ çalışmada topikal beta-bloker kullanılan yüzeyel İH hastalarının epidemiyolojik özellikleri ve tedavi etkinliğinin değerlendirilmesi amaçlanmıştır.

\section{Gereç ve yöntem}

Çocuk Hematoloji-Onkoloji Polikliniği'ne Nisan 2015-Mayıs 2017 tarihleri arasında başvuran, yaşları 0-36 ay arasında değişen ve yüzeyel hemanjiom tanısı alan hastalar çalışmaya dahil edildi. Hava yoluna ve orbitaya yerleşmiş, hayati organlarda bulunan, derin hemanjiomu olan hastalar çalışmaya alınmadı. Çalışma için Erzurum Bölge Eğitim ve Araştırma Hastanesi Etik Kurul onayı alındı. Yüzeysel hemanjiomu olan hastalara lezyon bölgesine $\% 0,5$ timolol maleate solüsyon, sabah ve akşam ikişer damla olacak şekilde uygulandı. Çalışmaya alınan hastaların yaşı, cinsiyeti, hemanjiomun büyüklüğü, lokalizasyonu, timolol maleat tedavi süresi, tedavi sonrası hemanjiom büyüklüğü geriye dönük olarak tarandı.

İstatistiksel analizler Statistical Package for the Social Sciences for Windows (SPSS) sürüm 18 yazılımı kullanılarak yapııdı. Değişkenlerin normal dağılıma uygunluğu görsel (histogram ve olasılık grafikleri) ve analitik yöntemlerle (Kolmogrov-Smirnov/Shapiro-Wilk testleri) incelendi. Tanımlayıcı analizler normal dağılan değişkenler için ortalama ve standart sapmalar, normal dağılmayan değişkenler için ortanca ve en küçük-en büyük değişkenler kullanılarak verildi. Ordinal değişkenler için frekans tabloları kullanıldı. Hemanjiomların tedavi öncesi ve sonrası boyutları student $t$ testi kullanılarak karşılaştırıldı. $P$ değerinin 0,05 'in altında olduğu durumlar istatiksel olarak anlamlı kabul edildi.

\section{Bulgular}

Çalışmaya 9'u (\%30) erkek, 21'i (\%70) kız, yaş ortancası 8,5 ay (2-36 ay) olan toplam 30 hasta alındı. Hastaların 19'unda $(\% 63,3)$ prematürite (<37 hafta), 20'sinde (\%66.7) düşük doğum ağırlığı öyküsü (<2500 gram) vardı. Preeklempsi/eklempsi öyküsü ise yoktu. Tüm hastaların aile öyküsünde multiparite mevcuttu.

Olguların 11 'i $(\% 36,7) 6$ ay altında, dokuzu (\%30) 6-12 ay arasında, 10'u (\%33,3) 12 ay 
üstünde idi (Tablo I). Çalışmamızdaki hastalarda hemanjiomların en sık yüz (n:10, \%33,3) ve gövdede (n:9, \%30) yerleştikleri görüldü (Tablo II). Hastalara ortalama $3,9 \pm 1,2$ ay timolol maleate tedavisi uygulandı. Hastaların yaş gruplarına göre tedavi süreleri Tablo IIl'de gösterilmiştir.

Tedavi öncesi hemanjiomların çapı ortalama $2,5 \pm 1,5 \mathrm{~cm}$ iken, tedavi sonrası 1,3 $\pm 0,8 \mathrm{~cm}$ olarak belirlendi ( $p<0,0001)$. Yaş gruplarına göre tedavi cevabı esas alındığında fark görülmedi ve her üç grupta da etkin küçülme gözlendi (Tablo IV). Hemanjiomların lokalizasyonuna göre tedavi yanıtı değerlendirildiğinde; başboyun, gövde, ekstremite ve vajen-vulva olmak üzere her bölgede hemanjiomlarda etkin tedavi yanıtı görüldü (Tablo V).

Timolol tedavisi uygulanan 30 hastanın sadece birinde $(\% 3,3)$ tedavi öncesi ve sonrasında değişiklik gözlenmedi. Dört hastada $(\% 13,3)$ hemanjiomlarda boyut değişikliği görülmezken belirgin renk değişikliği izlendi. Tedavi öncesi ve sonrası küçülme oranlarına göre bakıldığında dört hastanın $(\% 13,3)$ lezyonunda <\%25 küçülme, 8'inde $(\% 26,7)$ \%25-50 küçülme, beşinde (\%16,7) \%50-75 küçülme, beşinde $(\% 16,7)>\% 75$ küçülme ve üçünde (\%10) de tamamen kaybolma gözlendi (Tablo VI).

Tablo 1. Hastaların demografik özellikleri ve timolol kullanım süreleri

\begin{tabular}{ll}
\hline Cinsiyet (n) & Kadın: 21 \\
& Erkek: 9 \\
Yaş (ay) & Min: 2 \\
& Max: 36 \\
& Ortanca: 8,5 \\
Yaş grupları & $<6$ ay: $11(\% 36,7)$ \\
& $6-12$ ay: $9(\% 30)$ \\
& $>12$ ay: $10(\% 33,3)$ \\
İH'nin lokalizasyonu- $\mathbf{n}(\%)$ & Yüz- $10(\% 33,3)$ \\
& Gövde- $9(\% 30)$ \\
& Saçlı deri- $3(\% 10)$ \\
& Alt ekstremite- $4(\% 13,3)$ \\
& Üst ekstremite- $2(\% 6,7)$ \\
Timolol kullanma süresi (ay) (ortanca) & Vulva-vajen- $2(\% 6,7)$ \\
Timolol'ün yaş gruplarına göre kullanım süresi & $3,9+/-1,2$ \\
& $0-6$ ay: $3,5+/-1,3$ \\
& $6-12$ ay: $3,9+/-0,9$ \\
& $>12$ ay: $4,4+/-1,2$ \\
\hline
\end{tabular}

IH; İnfantil hemanjiom

Tablo 2. İH lokalizasyonları

\begin{tabular}{lcr}
\hline Hemanjiom bölge & $\mathbf{n : ~} \mathbf{3 0}$ & \% \\
\hline Yüz & 10 & 33,3 \\
Gövde & 9 & 30 \\
Saçlı deri & 3 & 10 \\
Alt ekstremite & 4 & 13,3 \\
Üst ekstremite & 2 & 6,7 \\
\hline Vajen & 2 & 6,7 \\
\hline
\end{tabular}


Tablo 3. Yaş gruplarına göre timolol kullanım süresi

\begin{tabular}{lllc}
\hline & 0-6 ay & 6-12 ay & $>12$ ay \\
Timolol kullanım süresi (Ort+/-SD) & $3,5+/-1,3$ & $3,9+/-0,9$ & $4,4+/-1,2$ \\
\hline
\end{tabular}

Ort $\pm S D ;$ Ortalama \pm Standart Deviasyon

Tablo 4. Yaşlara göre tedav öncesi ve sonrası tümör çapı (cm)

\begin{tabular}{lll}
\hline & Tedavi Öncesi (Ort+/-SD) & Tedavi Sonrası (Ort+/-SD) \\
\hline $\mathbf{0 - 6}$ ay & $2,4+/-1,4$ & $1,6+/-0,9$ \\
$\mathbf{6 - 1 2}$ ay & $2,5+/-1,8$ & $1,2+/-0,9$ \\
$\mathbf{> 1 2}$ ay & $2,5+/-1,4$ & $1,3+/-0,9$ \\
\hline
\end{tabular}

Ort $\pm S D ;$ Ortalama \pm Standart Deviasyon

Tablo 5. Tedavi yanıtı

\begin{tabular}{lccc}
\hline Lokalizasyon bölgesi & Hasta sayısı (n) & Tedavi öncesi çap & Tedavi sonrası çap \\
\hline Baş-boyun & 13 & $2,0+/-1 \mathrm{~cm}$ & $1,2+/-0,8 \mathrm{~cm}$ \\
Gövde & 9 & $2,6+/-1,4 \mathrm{~cm}$ & $1,1+/-0,7 \mathrm{~cm}$ \\
Ekstremite & 6 & $4,0+/-1,6 \mathrm{~cm}$ & $2,1+/-0,7 \mathrm{~cm}$ \\
Vajen-vulva & 2 & $1 \mathrm{~cm}$ & Kayboldu \\
\hline
\end{tabular}

Tablo 6. Tedavi sonrası total yanıt

\begin{tabular}{lll}
\hline & $\mathbf{n}$ & $\%$ \\
\hline Değişiklik yok & 1 & 3,3 \\
Sadece renk değişikliği & 4 & 13,3 \\
Boyutta < \%25 küçülme & 4 & 13,3 \\
Boyutta \% 25-50 küçülme & 8 & 26,7 \\
Boyutta \% 50-75 küçülme & 5 & 16,7 \\
Boyutta > \%75 küçülme & 5 & 16,7 \\
Tam kaybolma & 3 & 10 \\
\hline
\end{tabular}

\section{Tartışma}

Yüzeyel IH'de topikal timolol tedavisi son yıllarda özellikle tercih edilmeye başlanmıştır. Kullanım kolaylığı, yan etkilerinin az olması ve etkinliği tercih edilme nedenleridir. Özellikle 6 aya kadar olan hastalarda topikal timolol tedavisi hem etkili hem de güvenli bir tedavidir. Bizim çalışmamızda da hastaların hiçbiri tedaviyi bırakmamış, uyum sorunu yaşanmamıştır. Hiçbir hastada yan etki görülmemiş ve bir hasta hariç lezyonlarda gerileme görülmüştür.
İnantil hemanjiomlar tipik olarak erken bebeklik döneminde büyümeye başlarlar ve bunu spontan gerileme fazı izler. Proliferatif faz, yaşamın ilk 2 haftasında başlar, ardından bunu bir plato fazı izler. Gerileme fazı ilk yıldan sonra başlar ve 4-6 yıla kadar devam eder [11]. Hayatı tehdit etmeyen hemanjiomlarda 'bekle ve gör' tedavisi ile lezyonun kendiliğinden regrese olması beklenebilir. Ancak, kozmetik görünümün oluşturduğu rahatsızlık ve ailelerde oluşturduğu psikolojik baskı, etkinliği gösterilmiş ve yan etki profili az olan bir tedavi seçeneğini gündeme getirmiştir. 
Çalışmamızda tedaviye başlanma yaşları 0 ile 36 ay arasında idi. Proliferatif fazda tedavi en iyi sonuçları verirken, bu dönemde tedaviye başlamanın lezyon büyürken gelişmeyi durdurma, lezyonun boyutunu azaltma, çevredeki yapılar üzerindeki etkisini azaltma ve hastaların kozmetik özelliklerini iyileştirme etkisi de vardır. Biz de bu nedenle 6 ay altındaki hastaları da çalışmaya almayı uygun gördük. Xu ve arkadaşları [12] lokal propranolol ile tedaviye başlanan çocukların $0-3,3-6$ ve 6-10 aylık yaşları arasındaki tedavi yanıtlarının istatistiksel olarak anlamlı farklı olduğunu bulmuşlardır. Yu ve arkadaşları [13], 6 aylıktan önce timolol ile tedavi edilen hastaların 6 ile 12 ay arasında tedavi edilenlere göre daha yüksek lezyon gerileme oranlarına sahip olduklarını belirtmiştir. Ye ve arkadaşları da (14), 1-6 aylık hastalarda regresyon oranının, 7-12 aylık hastalara göre daha yüksek olduğunu, ancak etkinlik açısından farklııık olmadığını göstermişlerdir. Bizim çalışmamızda ise yaş grupları arasında tedavi cevabı arasında fark görülmedi. Her üç yaş grubunda da tedaviye benzer yanıt görüldü. Bu sonucun, bir hasta hariç tüm hastalarda lezyonlarda gerileme olmasından ve çalışmamızdaki hasta sayısının bu çalışmalara oranla düşük olmasından kaynaklanabileceğini düşündük. İlaç başlanmayan kontrol grubunun olmaması ve spontan regresyonyonların değerlendirilememesi de çalışmamızın kısıtlayıcı tarafı olarak değerlendirildi.

Infantil hemanjiomların patogenezi tam olarak anlaşılamamıştır ve muhtemelen multifaktöryeldir [11, 15]. İ için artmış risk faktörleri arasında beyaz ırk, dişi cinsiyet, prematürite, düşük doğum ağırlığı ve birden fazla gestasyon sayılabilir. Bizim çalışmamızda da kadın/erkek oranı yaklaşık 2,3/1 idi. Bazı çalışmalarda olduğu gibi, bizim hastalarımızda da İH lezyonları ağırlıklı olarak baş ve boyunda yer aldı. Ondokuz hasta prematürdü, 20 hasta düşük doğum ağırlığına sahipti. Tüm hastaların aile öyküsünde multiparite mevcuttu.

Hemanjiomlarda $\beta 1 / \beta 2$-adrenerjik antagonistlerle olan küçülme muhtemelen endotel hücreleri içinde, adenilsiklaz ve siklik AMP-bağımlı protein kinaz ile oluşan vazokonstrüksiyona bağlıdır. Hemanjiomların büyümesinin durması ve hatta küçülmesi, vasküler endotelyal büyüme faktörü, temel fibroblast büyüme faktörü ve matriks metalloproteinazlar gibi proanjiyojenik faktörlerin üretimi ile ilişkili olan hipoksi indüklenebilir faktör-1'in inhibisyonuna bağlanmıştır. Uzun süreli etkisi ise, $\beta$-blokajın, anti-apoptotik tirozin kinazın aracılık ettiği endotelyal hücre sağ kalım sinyalini inhibe ederek apoptozisi artırması şeklindedir. Gösterilmiştir ki, hemanjiomlar üzerindeki endotel hücreleri hem $\beta 1$ hem de $\beta 2$ adrenarjik reseptörleri eksprese etmektedir. Beta blokerler de bu yolağı inhibe ederek apopitozu artırmaktadır [16].

Çalışmamızda timolol kullanımı sonrası 8 aylık bir vaka hariç hemanjiom rengi ve büyüklüğünde belirgin gerileme olmuştur. Gerileme gözlenmeyen bu vakada hemanjiom saçlı deride bulunmaktaydı. Bu nedenle ilacın uygulanmasında yanlışlık yapılmış olabileceğini ve lezyonda gerekli emilimin sağlanamadığını düşündük. Tamamen gerileyen üç hastanın ikisinin lezyon bölgesi ekstremitelerde, birinin ise gövdede bulunmaktaydı. Hastalardan ikisi 6 ayın altında yaş grubuna sahipti. Biri ise 6-12 ay yaş grubundaydı. Hastaların tedavilerine erken proliferatif fazda başlanmış olması, lezyonun büyümesini durdurmamıza katkı sağlamış olabilir.

Timolol kullanımı boyunca herhangi bir yan etki görülmemiştir. Ancak bazı çalışmalarda uyku bozukluğu ve kaşıntı gibi yan etkiler bildirilmiştir [17-19]. Sistemik beta bloker kullanımı sonrasında çok daha ciddi yan etkiler bildirildiğinden, tedaviye başlanırken hastaların hastaneye yatırılarakgözlenmesi gerekmektedir. Oysa topikal beta bloker kullanımında böyle bir gereklilik görülmemiş bu da aile ve hastanın ilaç kullanım uyumunu artırmıştır.

Çalışmamıza sadece yüzeyel hemanjiomlu hastalar dahil edildiği için yan etki olasılığı yüksek olan oral B-blokerler tercih edilmemiştir. $\mathrm{Bu}$ nedenle topikal timolol tedavisi alan hastaların oral propronolol tedavisi alan hastalarla karşılaştırı Iması yapılamamıştır.

Sonuç olarak; kullanımının kolay olması, sistemik yan etkilerinin az denecek kadar nadir görülmesi ve lezyonda belirgin gerilemeye yol açması nedeni ile yüzeyel hemanjiyomlu hastalarda topikal timolol kullanımı ümit vadetmektedir.

Çıkar ilişkisi: Yazarlar çıkar ilişkisi olmadığını beyan eder. 


\section{Kaynaklar}

1. Drolet BA, Swanson EA, Frieden IJ. Infantile hemangiomas: an emerging health issue linked to an increased rate of low birth weight infants. J Pediatr 2008;153:712-715. https://doi.org/10.1016/j. jpeds.2008.05.043

2. George A, Mani V, Noufal A. Update on the classification of hemangioma. J Oral Maxillofac Pathol 2014;18:117120. https://doi.org/10.4103/0973-029X.141321

3. Drolet BA, Esterly NB, Frieden IJ. Hemangiomas in children. N Engl J Med 1999;341:173-181. https://doi. org/10.1056/NEJM199907153410307

4. Itinteang T, Withers AHJ, Davis PF, Tan ST. Biology of infantile hemangioma. Front Surg 2014;1-38. https:// doi.org/10.3389/fsurg.2014.00038

5. Li J, Chen X, Zhao S, et al. Demographic and clinical characteristics and risk factors for infantile hemangioma: a Chinese case-control study. Arch Dermatol 2011;147:1049-1056. https://doi.org/10.1001/ archdermatol.2011.122

6. Haggstrom AN, Drolet BA, Baselga E, et al. Prospective study of infantile hemangiomas: demographic, prenatal, and perinatal characteristics. J Pediatr 2007;150:291294. https://doi.org/10.1016/j.jpeds.2006.12.003

7. Cheng CE, Friedlander SF. Infantile hemangiomas, complications and treatments. Semin Cutan Med Surg 2016;35:108-116. https://doi.org/10.12788/j. sder.2016.050

8. Zhang Q, Chantasart D, Li SK. Evaluation of betablocker gel and effect of dosing volüm efor topical delivery. J Pharm Sci 2015;104:1721-1731. https://doi. org/10.1002/jps.24390

9. Xue K, Hildebrand GD. Deep periocular infantile capillary hemangiomas responding to topical application of timolol maleate, $0.5 \%$, drops. JAMA Ophthalmol 2013;131:1246-1248. https://doi. org/10.1001/jamaophthalmol

10. Painter SL, Hildebrand GD. Review of topical beta blockers as treatment for infantile hemangiomas. Surv Ophthalmol 2016;61:51-58. https://doi.org/10.1016/j. survophthal.2015.08.006

11. Greenberger S, Bischoff J. Pathogenesis of infantile haemangioma. Br J Dermatol 2013;169:12-19. https:// doi.org/10.1111/bjd.12435

12. Xu G, Lv R, Zhao Z, Huo R. Topical propranolol for treatment of superficial infantile hemangiomas. J Am Acad Dermatol 2012;67:1210-1213. https://doi. org/10.1016/j.jaad.2012.03.009

13. 13.Yu L, Li S, Su B, et al. Treatment of superficial infantile hemangiomas with timolol: evaluation of short-term efficacy and safety in infants. Exp Ther Med 2013;6:388-390. https://doi.org/10.3892/ etm.2013.1176
14. Ye $X X$, Jin $Y B$, Lin $X X$, et al. Topical timolol in the treatment of periocular superficial infantile hemangiomas: a prospective study. Zhonghua Zheng Xing Wai Ke Za Zhi 2012:28:161-164.

15. Janmohamed SR, Madern GC, de Laat PC, Oranje AP. Educational paper: pathogenesis of infantile haemangioma, an update 2014 (part I). Eur J Pediatr 2015;97-103. https://doi.org/10.1007/s00431-0142403-6

16. Chim H, Armijo BS, Miller E, Gliniak C, Serret MA, Gosain AK. Propranolol induces regression of hemangioma cell sthrough HIF- 1 alpha-mediated inhibition of VEGF-A. Ann Surg 2012;256:146-156. https://doi.org/10.1097/SLA.0b013e318254ce7a

17. Chakkittakandiyil A, Phillips R, Frieden IJ, et al. Timolol maleate $0.5 \%$ or $0.1 \%$ gel-forming solution for infantile hemangiomas: a retrospective, multicenter, cohortstudy. Pediatr Dermatol 2012;29:28-31. https:// doi.org/10.1111/j.1525-1470.2011.01664.x

18. Khunger $\mathrm{N}$, Pahwa $\mathrm{M}$. Dramatic response to topical timolol lotion of a large hemifacial infantile haemangioma associated with PHACE syndrome. $\mathrm{Br}$ J Dermatol 2011;164:886-888. https://doi.org/10.1111/ j.1365-2133.2010.10177.x

19. Ariwibowo L, Danarti R. Comparison of efficacy between topical corticosteroid, timolol maleat $0.5 \%$ eye drop, and education observation in managing infantile hemangioma. Regional Conference of Dermatology (Asian Australasian) and 6th Annual Meeting of the Asian Academy of Dermatology and Venereology (abstract). Danang 2014.

'İnfantil hemanjiomların tedavisinde topikal Beta-Blokerlerin etkinliği' başlıklı çalışmamız, 12. Ulusal Pediatrik Hematoloji Kongresinde, 2019 yılında poster olarak sunulmuştur.

Etik kurul onayı: Erzurum Bölge Eğitim ve Araştırma Hastanesi Etik Kurulu'ndan 22.03.2019 karar tarih ve 2018/288 sayısı ile onay alınmıştır.

\section{Yazarların katkıları}

G.P.R. çalışmanın ana fikrini ve hipotezini kurgulamıştır. G.P.R. ve A.F. teoriyi geliştirmiş ve materyel metod bölümünü düzenlemişlerdir. Sonuçlar kısmınındaki verilerin değerlendirmesini G.P.R. ve A.A. yapmışlardır. Makalenin tartışma bölümü G.P.R. tarafından yazılmış, A.Ç. ve B.P.V. gözden geçirip gerekli düzeltmeleri yapmış ve onaylamıştır. Ayrıca tüm yazarlar çalışmanın tamamını tartışmış ve son halini onaylamıştır. 